\title{
Salmonella typing in New South Wales: current methods and application of improved epidemiological tools
}

\section{Qinning Wang ${ }^{\mathrm{A}}$, Robert Chiew ${ }^{\mathrm{A}}$, Peter Howard ${ }^{\mathrm{A}}$ and Gwendolyn L. Gilbert ${ }^{\mathrm{A}, \mathrm{B}}$}

\author{
${ }^{\mathrm{A}}$ Centre for Infectious Diseases and Microbiology, \\ Institute of Clinical Pathology and Medical Research, \\ Westmead Hospital \\ ${ }^{\mathrm{B} C o r r e s p o n d i n g ~ a u t h o r ~ e m a i l: ~ l . g i l b e r t @ u s y d . e d u . a u ~}$
}

more invasive and salmonellae can be isolated from blood, urine or other extra-intestinal sites. Salmonellae also infect or colonise many animal species and most cases of human salmonellosis are acquired from raw, undercooked or contaminated animal products. ${ }^{2-4}$

The most virulent serovars are $S$. enterica serovar, Typhi and $S$. Paratyphi A and B, the aetiological agents of enteric fever (typhoid and paratyphoid fever respectively). ${ }^{5}$ Salmonellae constitute the largest group of notifiable enteric pathogens reported in NSW, despite the likelihood of cases being grossly underreported. ${ }^{6}$ Between 1991-2006, an average of 1800 cases were notified in NSW each year (or 12 to 48 cases per 100000) and these probably represent less than 10 per cent of cases. ${ }^{6,7}$

\section{Laboratory diagnosis and culture identification}

Laboratory diagnosis of salmonellosis is usually made through the culture of stools. Specimens are inoculated onto selective media (xylose-lysine-decarboxylase agar, [CHROMagar, Paris] and selenite-F [Difco, Le Pont du Claix, France]) and the salmonella-like isolates are identified. ${ }^{8,9}$ Blood cultures are also performed for suspected enteric fever and other invasive salmonellosis, and in septic cases where enteric fever or invasive salmonellosis can be the cause but usually are not suspected at presentation. Biochemical tests to identify isolates are often performed by commercial bacterial identification systems. These systems provide automated species identification and antibiotic susceptibility testing, but are less reliable for enteric pathogens than the conventional methods of individual tube biochemical tests and disc diffusion susceptibility testing. In a recent internal review of results generated by the Phoenix 100 (Becton Dickinson, Franklin Lakes, NJ), 15 per cent of 84 salmonella isolates were initially incorrectly identified (unpublished data, Centre for Infectious Diseases and Microbiology).

Salmonella is a genus of Gram-negative bacteria in the family Enterobacteriaceae. The classification of salmonellae is confusing and controversial, but most belong to a single species, Salmonella enterica, which is divided into more than 2500 serovars. ${ }^{1}$ Many of these cause human salmonellosis, a gastrointestinal illness of significant public health importance. Salmonellosis commonly presents with diarrhoea, headache, abdominal cramps, fever, nausea and vomiting. A small percentage of infections are
In NSW, up to 100 public and private diagnostic laboratories submit Salmonella cultures for serotyping to the NSW Enteric Reference Laboratory at the Centre for Infectious Diseases and Microbiology Laboratory Service. All isolates are first tested to confirm their identity. The traditional tube methods of biochemical testing are the gold standard for reference laboratories. ${ }^{9}$ 


\section{Salmonella typing in NSW}

Although serotype identification is not required for patient management, it is an important epidemiological tool for outbreak investigations and surveillance. For common serovars, further subtyping is needed and phage typing is currently most commonly used. Serotyping and phage typing are the basis of Salmonella reporting to the National Enteric Pathogens Surveillance Scheme. In NSW, results are reported electronically to the NSW Department of Health.

\section{Serotyping}

Serotyping involves the use of specific diagnostic sera and slide agglutination, the results of which are read in a light box. The Kauffman and White Salmonella classification scheme is based on cell wall $(\mathrm{O})$ and flagellar $(\mathrm{H})$ antigens and, for a few serovars (notably $S$. Typhi and $S$. Dublin), a capsular (Vi) antigen. ${ }^{10}$ Common $\mathrm{O}$ antigens are the basis of serogroups and subgroups. Flagellar antigens create greater serotype diversity, and are expressed as phase I, phase II or phase I and II. Various combinations of the numerous $\mathrm{O}$ and $\mathrm{H}$ antigens contribute to over 2500 serovars, each of which can be described by a 'formula' based on these antigens - for example: $S$. Typhimurium is (O) 1,4,5,12:(H)i:1,2; $S$. Enteritidis is 1,9,12: g,m:-; and $S$. Typhi is 9,12 ,Vi:d:- ${ }^{1,10}$

There were 1500-2000 human isolates typed by the
NSW Enteric Reference Laboratory for each year between 2001 and 2005, representing 86-104 serovars. The majority of cases of human salmonellosis are caused by a small number of serovars. The 10 most common serovars identified by the NSW Enteric Reference Laboratory are listed in Table 1, and account for 75-80 per cent of isolates. $S$. Typhimurium accounts for $50-55$ per cent of all cases in NSW. Other common serovars include $S$. Enteritidis, $S$. Virchow and $S$. Infantis (Table 1).

\section{Phage typing}

Bacteriophages are viruses that may be present in certain bacteria without causing damage, but that under certain circumstances, or when applied to a susceptible bacterial culture, can kill (or lyse) the bacteria. Bacteriophage (phage) typing refers to a standard method of characterising selected Salmonella serovars. It is based on patterns of lysis and uses an international set of phages. The phage typing scheme for $S$. Typhimurium was developed 30 years ago by Anderson et al. and is still widely used. ${ }^{11}$ Two laboratories perform phage typing on a small number of serovars for NSW: the Microbiological Diagnostic Unit, Melbourne ( $S$. Typhimurium, $S$. Typhi, $S$. Paratyphi A and B including bioser java, $S$. Enteritidis, $S$. Virchow, $S$. Hadar); and the Australian Salmonella Reference Centre, Adelaide ( $S$. Heidelberg, $S$. Bovismorbificans).

Phage typing is based on the fact that most Salmonella strains are infected with one or more bacterial viruses

Table 1. Ten most common Salmonella serovars isolated from humans and identified in the NSW between 2001 and 2005 $n=$ denotes number of records for that year. The percentage of each Salmonella serovar for the year is given in brackets.

\begin{tabular}{|c|c|c|c|c|c|}
\hline Ranking & $\begin{array}{c}2001 \\
(n=1590)\end{array}$ & $\begin{array}{c}2002 \\
(n=1802)\end{array}$ & $\begin{array}{c}2003 \\
(n=1774)\end{array}$ & $\begin{array}{c}2004 \\
(n=2029)\end{array}$ & $\begin{array}{c}2005 \\
(n=2047)\end{array}$ \\
\hline 1 & $\begin{array}{l}\text { S. Typhimurium } \\
(51.2 \%)\end{array}$ & $\begin{array}{l}\text { S. Typhimurium } \\
(51.9 \%)\end{array}$ & $\begin{array}{l}\text { S. Typhimurium } \\
(52.1 \%)\end{array}$ & $\begin{array}{l}\text { S. Typhimurium } \\
(56.1 \%)\end{array}$ & $\begin{array}{l}\text { S. Typhimurium } \\
\text { (53.1\%) }\end{array}$ \\
\hline 2 & $\begin{array}{l}\text { S. Enteritidis } \\
(4.4 \%)\end{array}$ & $\begin{array}{c}\text { S. Bovismorbificans } \\
(4.6 \%)\end{array}$ & $\begin{array}{c}\text { S. Infantis } \\
(5.8 \%)\end{array}$ & $\begin{array}{l}\text { S. Enteritidis } \\
(4.1 \%)\end{array}$ & $\begin{array}{l}\text { S. Enteritidis } \\
(5.2 \%)\end{array}$ \\
\hline 3 & $\begin{array}{c}\text { S. Birkenhead } \\
(4.1 \%)\end{array}$ & $\begin{array}{l}\text { S. Virchow } \\
(4.5 \%)\end{array}$ & $\begin{array}{l}\text { S. Virchow } \\
(3.7 \%)\end{array}$ & $\begin{array}{l}\text { S. Virchow } \\
(4.0 \%)\end{array}$ & $\begin{array}{l}\text { S. Virchow } \\
(3.7 \%)\end{array}$ \\
\hline 4 & $\begin{array}{l}\text { S. Virchow } \\
(3.5 \%)\end{array}$ & $\begin{array}{c}\text { S. Montevideo } \\
(3.6 \%)\end{array}$ & $\begin{array}{c}\text { S. Bovismorbificans } \\
(2.6 \%)\end{array}$ & $\begin{array}{l}\text { S. Infantis } \\
(2.5 \%)\end{array}$ & $\begin{array}{l}\text { S. Infantis } \\
(2.6 \%)\end{array}$ \\
\hline 5 & $\begin{array}{c}\text { S. Bovismorbificans } \\
(3.5 \%)\end{array}$ & $\begin{array}{l}\text { S. Enteritidis } \\
(3.1 \%)\end{array}$ & $\begin{array}{l}\text { S. Chester } \\
(2.6 \%)\end{array}$ & $\begin{array}{c}\text { S. Bovismorbificans } \\
(2.2 \%)\end{array}$ & $\begin{array}{l}\text { S. subsp. } 1 \text { ser } 16: \text { Iv:- } \\
(2.1 \%)\end{array}$ \\
\hline 6 & $\begin{array}{l}\text { S. Stanley } \\
(3.4 \%)\end{array}$ & $\begin{array}{l}\text { S. Infantis } \\
(2.2 \%)\end{array}$ & $\begin{array}{l}\text { S. Saintpaul } \\
(2.2 \%)\end{array}$ & $\begin{array}{l}\text { S. Typhi } \\
(1.9 \%)\end{array}$ & $\begin{array}{c}\text { S. Bovismorbificans } \\
(1.8 \%)\end{array}$ \\
\hline 7 & $\begin{array}{l}\text { S. Infantis } \\
(2.4 \%)\end{array}$ & $\begin{array}{l}\text { S. Potsdam } \\
(2.1 \%)\end{array}$ & $\begin{array}{c}\text { S. Enteritidis } \\
(2.1 \%)\end{array}$ & $\begin{array}{l}\text { S. Saintpaul } \\
(1.8 \%)\end{array}$ & $\begin{array}{l}\text { S. Saintpaul } \\
(1.6 \%)\end{array}$ \\
\hline 8 & $\begin{array}{l}\text { S. Saintpaul } \\
(2.1 \%)\end{array}$ & $\begin{array}{l}\text { S. Saintpaul } \\
(1.9 \%)\end{array}$ & $\begin{array}{c}\text { S. Singapore } \\
(1.3 \%)\end{array}$ & $\begin{array}{c}\text { S. subsp. } 1 \text { ser } 16: \text { Iv:- } \\
(1.7 \%)\end{array}$ & $\begin{array}{l}\text { S. Typhi } \\
(1.5 \%)\end{array}$ \\
\hline 9 & $\begin{array}{c}\text { S. Singapore } \\
(1.4 \%)\end{array}$ & $\begin{array}{c}\text { S. Birkenhead } \\
(1.8 \%)\end{array}$ & $\begin{array}{c}\text { S. subsp. } 1 \text { ser } 16: \text { Iv:- } \\
(1.9 \%)\end{array}$ & $\begin{array}{l}\text { S. Chester } \\
(1.4 \%)\end{array}$ & $\begin{array}{l}\text { S. Stanley } \\
(1.4 \%)\end{array}$ \\
\hline 10 & $\begin{array}{l}\text { S. Typhi } \\
(1.4 \%)\end{array}$ & $\begin{array}{c}\text { S. Agona } \\
\text { (1.6\%) }\end{array}$ & $\begin{array}{c}\text { S. Montevideo } \\
(1.7 \%)\end{array}$ & $\begin{array}{c}\text { S. Singapore } \\
(1.3 \%)\end{array}$ & $\begin{array}{c}\text { S. Hvittingfoss } \\
(1.3 \%)\end{array}$ \\
\hline No. of Serovars & 86 & 98 & 95 & 102 & 104 \\
\hline
\end{tabular}


known as bacteriophages (or phages), which either remain, silently, in the bacterial cell or lyse it and are released. The susceptibility of a particular Salmonella strain to infection and lysis by different phages varies according to which phages it already contains. For example, for $S$. Typhimurium a set of 34 phages is used to identify 207 phage types. Phages are 'spotted' on to a lawn culture of bacteria and incubated overnight. 'Punched out' areas without growth, in the otherwise even lawn culture, indicate lysis of the salmonella strain by the corresponding phage. The combination of phages to which a particular Salmonella isolate is susceptible determines its phage type.

Standard phage typing sets are maintained at the Central Public Health Laboratory of the Health Protection Agency in the United Kingdom. Historically, the sets have been made available to a limited number of reference laboratories, usually only one per country. The need to refer isolates interstate for phage typing after serotyping has been performed causes potential delays of 2-4 weeks before results are available. In addition, phage typing has limited discriminatory power for some serovars, including $S$. Typhimurium, and some isolates are non-typeable or the pattern they produce does not fit any recognised phage type. When this occurs, it is reported as RDNC: reacts does not conform.

There are numerous potential delays in the process of identification and typing of salmonellae, and 4-5 weeks may elapse from the time of consuming contaminated food, until results required for public health action are available (see Box 1, for $S$. Typhimurium). As a result, the chances of obtaining a reliable food history and identifying food sources are very low. This is a particular problem for common serovars like $S$. Typhimurium, for which it is difficult to identify outbreaks against a background of high endemicity.

\section{Molecular typing: the future of Salmonella typing?}

Many molecular typing methods have been used for further discrimination of Salmonella serovars and phage types, but these methods are generally slow and expensive. Molecular typing has variable reproducibility and discriminatory power but an advantage is that it can be performed by larger laboratories, so there is no need for interstate referral.

Pulsed-field gel electrophoresis has been widely used and is regarded as the 'gold standard' for Salmonella genotyping. ${ }^{12}$ It is the basis for the US Centers for Disease Control and Prevention's 'PulseNet', an international surveillance system for Salmonella and other foodborne pathogens. However, pulsed-field gel electrophoresis is time-consuming, its ability to distinguish subtypes within $S$. Typhimurium is limited and comparison of results between laboratories and over long time periods requires painstaking standardisation of methods and expensive image-recognition software. Amplified-fragment length polymorphism is more discriminatory but, like pulsedfield gel electrophoresis, is technically difficult, slow, expensive and requires specialised equipment. ${ }^{13,14}$ Multilocus sequence typing is expensive and has limited discriminatory ability because it uses highly conserved housekeeping genes. ${ }^{15}$

Recently multilocus variable-number tandem-repeats analysis (MLVA) has been developed for various Salmonella serovars, including $S$. Typhimurium, and has the potential to become the method of choice in many laboratories (for more detail on MLVA see Gilbert, 'Using MLVA to type strains of Salmonella Typhimurium in New South Wales' in this issue). ${ }^{16-20}$ This technique has a high discriminatory power to differentiate Salmonella strains within phage types. Even genetically homogenous phage types such as $S$. Typhimurium definitive type (DT) 104 can be differentiated. ${ }^{21} \mathrm{NSW}$ introduced this method for routine typing of $S$. Typhimurium in May 2006 and, by November 2007, over 1500 isolates, comprising more than 60 phage types, had been typed using this method. More than 400 MLVA types and dozens of outbreaks have been identified. The largest outbreaks include $S$. Typhimurium outbreaks in a catering college in the Blue Mountains area and another in a hot bread shop in Homebush, in which more than 300 patients were involved (unpublished data; Centre for Infectious Diseases and Microbiology-Public Health, Salmonella outbreak molecular typing report, November 2006-May 2007). In addition, MLVA was used to investigate a nationwide $S$. Saintpaul outbreak in 2006.

The challenge posed by $S$. Typhimurium and the need to develop a practical, cost-effective, rapid strain typing system is the rationale for a post-doctoral research project at Centre for Infectious Diseases and Microbiology (CIDM) Public Health. For simultaneous detection, identification and typing of $S$. Typhimurium isolates, we have developed a multiplex PCR-based reverse line blot hybridisation system. The system is based on known phage sequences and phage type-specific amplified-fragment length polymorphism fragments. ${ }^{13,22-24}$ Most common $S$. Typhimurium phage types can be identified by their reverse line blot patterns. Preliminary testing of the system with 168 selected $S$. Typhimurium isolates (representing 46 phage types), produced 102 reverse line blot patterns.

This method has a discriminatory power similar to that of MLVA and is suitable for epidemiological investigation of outbreaks. The reverse line blot data are stored as digital profiles and data libraries can be set up so that reverse line blot patterns can be compared historically and geographically. Once sample DNA is extracted, results are available within 24 hours. The multiplex PCR-based reverse line blot hybridisation system has been applied in several out- 
break investigations in NSW. It rapidly identified human outbreak isolates and isolates from suspect food sources, and successfully predicted the phage type involved more than a week before the phage typing results were available.

In addition, the multiplex PCR-based reverse line blot hybridisation system allows a total of 43 samples to be tested in a single run and, with current available resources, up to two runs can be performed each week. In future, this typing method can be further expanded by adding more gene markers to the system. This will improve its discriminatory power and provide a genetic marker base for further development of a microarray system that is capable of simultaneously identifying serovar and phage type, and distinguishing different Salmonella strains.

\section{Conclusion}

A major focus in the investigation of food poisoning is timeliness in obtaining a laboratory result and the usefulness of the result for identifying or pinpointing the likelihood of an outbreak. Serotyping still remains a useful initial tool for rapid differentiation of broad groups of Salmonella into serovars. The results of our outbreakbased molecular studies strongly suggest that due to its limited discriminatory ability, phage typing will eventually be replaced by reliable molecular typing methods. This will also overcome the delays and cost of sending cultures to interstate reference laboratories. The combination of current MLVA typing and the new multiplex PCR-based reverse line blot hybridisation system will become the method of choice for improving outbreak investigation and surveillance, and will lead to better foodborne disease control in NSW.

\section{References}

1. Davos D. Salmonella. In: CJ McIver, editor. A compendium of laboratory diagnostic methods for common and unusual enteric pathogens: an Australian perspective. Melbourne: Australian Society for Microbiology 2005, pp. 119-35.

2. McPherson ME, Fielding JE, Telfer B, Stephens N, Combs BG, Rice BA et al. A multi-jurisdiction outbreak of Salmonella Typhimurium phage type 135 associated with purchasing chicken meat from a supermarket chain. Commun Dis Intell 2006; 30(4): 449-55.

3. Stephens N, Sault C, Firestone SM, Lightfoot D, Bell C. Large outbreaks of Salmonella Typhimurium phage type 135 infections associated with the consumption of products containing raw egg in Tasmania. Commun Dis Intell 2007; 31(1): 118-24.

4. Vanselow BA, Hornitzky MA, Walker KH, Eamens GJ, Bailey GD, Gill PA et al. Salmonella and on-farm risk factors in healthy slaughter-age cattle and sheep in eastern Australia. Aust Vet J 2007; 85(12): 498-502. doi:10.1111/j.17510813.2007.00233.x

5. Centers for Disease Control and Prevention. Disease Listing: Salmonellosis and Typhoid Fever. Available at http://www.cdc.gov/NCIDOD/DBMD/diseaseinfo/default.htm. Accessed 10 January 2008.
6. National Notifiable Diseases Surveillance System. Communicable Diseases Australia: Notifications for all Diseases by State \& Territory and Year: 1991-2006. Available from: http://www9.health.gov.au/cda/Source/Rpt_2_sel.cfm. Accessed 10 January 2008.

7. Yohannes K, Dalton C, Halliday K, Unicomb L, Hall G. Salmonellosis in Australia; the societal cost of illness [Master of Applied Epidemiology thesis]. Canberra: Australian National University; 2003.

8. Maddocks S, Olma T, Chen S. Comparison of CHROMagar Salmonella medium and xylose-lysine-desoxycholate and Salmonella-Shigella agars for isolation of Salmonella strains from stool samples. J Clin Microbiol 2002; 40(8): 2999-3003. doi:10.1128/JCM.40.8.2999-3003.2002

9. William HE. Edwards and Ewing's identification of enterobacteriaceae. 4th Edition. New York: Elsevier Science, 1986.

10. Popoff MY, Bockemuhl J, McWhorter-Murlin A. Supplement 1992 (no. 36) to the Kauffmann-White scheme. Res Microbiol 1993; 144(6): 495-8. doi:10.1016/0923-2508(93)90058-A

11. Anderson ES, Ward LR, Saxe MJ, de Sa JD. Bacteriophagetyping designations of Salmonela Typhimurium. J Hyg (Lond) 1977; 78(2): 297-300.

12. Guerra B, Schrors P, Mendoza MC. Application of PFGE performed with $\mathrm{XbaI}$ to an epidemiological and phylogenetic study of Salmonella serotype Typhimurium. Relations between genetic types and phage types. New Microbiol 2000; 23(1): $11-20$.

13. Hu H, Lan R, Reeves PR. Fluorescent amplified fragment length polymorphism analysis of Salmonella enterica serovar Typhimurium reveals phage-type-specific markers and potential for microarray typing. J Clin Microbiol 2002; 40(9): 3406-15. doi:10.1128/JCM.40.9.3406-3415.2002

14. Lindstedt BA, Heir E, Vardund T, Kapperud G. Fluorescent amplified-fragment length polymorphism genotyping of Salmonella enterica subsp. enterica serovars and comparison with pulsed-field gel electrophoresis typing. J Clin Microbiol 2000; 38(4): 1623-7.

15. Fakhr MK, Nolan LK, Logue CM. Multilocus sequence typing lacks the discriminatory ability of pulsed-field gel electrophoresis for typing Salmonella enterica serovar Typhimurium. J Clin Microbiol 2005; 43(5): 2215-9. doi:10.1128/ JCM.43.5.2215-2219.2005

16. Cho S, Boxrud DJ, Bartkus JM, Whittam TS, Saeed M. Multiple-locus variable-number tandem repeat analysis of Salmonella Enteritidis isolates from human and non-human sources using a single multiplex PCR. FEMS Microbiol Lett 2007; 275(1): 16-23. doi:10.1111/j.1574-6968.2007.00875.x

17. Lindstedt BA, Vardund T, Aas L, Kapperud G. Multiple-locus variable-number tandem-repeats analysis of Salmonella enterica subsp. enterica serovar Typhimurium using PCR multiplexing and multicolor capillary electrophoresis. J Microbiol Methods 2004; 59(2): 163-72. doi:10.1016/ j.mimet.2004.06.014

18. Liu Y, Lee MA, Ooi EE, Mavis Y, Tan AL, Quek HH. Molecular typing of Salmonella enterica serovar typhi isolates from various countries in Asia by a multiplex PCR assay on variable-number tandem repeats. J Clin Microbiol 2003; 41(9): 4388-94. doi:10.1128/JCM.41.9.4388-4394.2003

19. Witonski D, Stefanova R, Ranganathan A, Schutze GE, Eisenach KD, Cave MD. Variable-number tandem repeats that are useful in genotyping isolates of Salmonella enterica subsp. enterica serovars Typhimurium and Newport. J Clin Microbiol 2006; 44(11): 3849-54. doi:10.1128/JCM.00469-06 
20. Gilbert L. Using MLVA to type strains of Salmonella Typhimurium in New South Wales. NSW Pub Health Bull 2008; 19(1-2): 29-31. doi:10.1016/j.mimet.2006.07.004

21. Lindstedt BA, Heir E, Gjernes E, Kapperud G. DNA fingerprinting of Salmonella enterica subsp. enterica serovar Typhimurium with emphasis on phage type DT104 based on variable number of tandem repeat loci. J Clin Microbiol 2003; 41(4): 1469-79. doi:10.1128/JCM.41.4.1469-1479.2003

22. Mikasova E, Drahovska H, Szemes T, Kuchta T, Karpiskova R, Sasik M et al. Characterization of Salmonella enterica serovar Typhimurium strains of veterinary origin by molecular typing methods. Vet Microbiol 2005; 109(1-2): 113-20. doi:10.1016/j.vetmic.2005.05.006
23. Ross IL, Heuzenroeder MW. Discrimination within phenotypically closely related definitive types of Salmonella enterica serovar Typhimurium by the multiple amplification of phage locus typing technique. J Clin Microbiol 2005; 43(4): 1604-11. doi:10.1128/JCM.43.4.1604-1611.2005

24. Lan R, Stevenson G, Donohoe K, Ward L, Reeves PR. Molecular markers with potential to replace phage typing for Salmonella enterica serovar Typhimurium. J Microbiol Methods 2007; 68(1): 145-56. doi:10.1016/j.mimet.2006.07.004 